\title{
Isolation, characterization and quantification of a pentacyclic triterpinoid compound ursolic acid in Scabiosa palaestina L. distributed in the north of Iraq
}

\author{
Amjed Haseeb Khamees* \& Enas J Kadhim \\ Department of Pharmacognocy and Medicinal Plants, College of Pharmacy, University of Baghdad 10001, Baghdad, Iraq \\ ^Email: amjed.haseeb.khamees@gmail.com
}

\section{OPEN ACCESS}

\section{ARTICLE HISTORY}

Received: 20 July 2021

Accepted: 16 October 2021

Available online

Version 1 (Early Access): 04 December 2021

Version 2.0: 01 January 2022

\section{Check for updates}

\section{Additional information}

Peer review: Publisher thanks Sectional Editor and the other anonymous reviewers for their contribution to the peer review of this work.

Reprints \& permissions information is available at https://horizonepublishing.com/ journals/index.php/PST/open_access_policy

Publisher's Note: Horizon e-Publishing Group remains neutral with regard to jurisdictional claims in published maps and institutional affiliations.

Indexing: Plant Science Today, published by Horizon e-Publishing Group, is covered by Scopus, Web of Science, BIOSIS Previews, Clarivate Analytics, etc. See https:// horizonepublishing.com/journals/index.php/ PST/indexing_abstracting

Copyright: () The Author(s). This is an openaccess article distributed under the terms of the Creative Commons Attribution License, which permits unrestricted use, distribution and reproduction in any medium, provided the original author and source are credited (https://creativecommons.org/licenses/ by/4.0/)

\section{CITE THIS ARTICLE}

Khamees A H, Kadhim E J. Isolation, characterization and quantification of a pentacyclic triterpinoid compound ursolic acid in Scabiosa palaestina L. distributed in the north of Iraq. Plant Science Today. 2022;9(1):178-182. https://doi.org/10.14719/pst.1398

\begin{abstract}
Ursolic acid (UA, $3 \beta$-hydroxy-urs-12-en-28-oic acid) are isomeric triterpenic acids. The high quantities of pentacyclic triterpenoids in Scabiosa species seems to be obvious and there is an evidence that most of pentacyclic triterpenoids that have been isolated are saponins. This is one of the most important characteristic of the genus Scabiosa, the main aglycones are ursolic acid and oleanolic acid. In the current study, isolation from the aerial part and roots of Scabiosa palaestina L. was performed using Preparative HPLC. Furthermore, detection and quantitation of ursolic acid was performed by high performance thin layer chromatography (HPTLC). The identification of isolated triterpenoid involves two methods including FT-IR coupled with LC-MS/MS that have been used for the simultaneous determination of the isolated UA. Quantitative analysis of Ursolic acid content in chloroform fractions revealed that both of the aerial parts and roots contain comparable concentration of 0.052 and $0.054 \mathrm{mg} / \mathrm{ml}$ respectively. The FT-IR and LC-MS/MS spectra of the isolated compound shows good agreement with those reported in literatures of Ursolic acid. Quantitative concentration of UA in chloroform fraction revealed that aerial parts and roots contain comparable concentrations and the spectral data for the isolated unknown were in good agreement with those reported in literature of UA.
\end{abstract}

\section{Keywords \\ HPTLC, Pentacyclic triterpenoids, Ursolic acid}

\section{Introduction}

Genus Scabiosa L. (Family: Caprifoliaceae) consists of 618 species (1). The major species of $S$. are widely spread in the Mediterranean area and some species were traditionally used as a medication in many countries. abundance of secondary metabolites in Scabiosa species such as flavonoids, iridoids and pentacyclic triterpenoids may contribute to their use in folkloric medicine (2). S. palaestina produces pentacyclic triterpenoids like ursolic acid figure 1 and oleanolic acid, terpenoids are considered as one of the important and diverse metabolites, which have significant pharmacological and medicinal activities (3) in addition to their role in the pharmaceutical industries for different purposes (4). From the medicinal perspective, triterpenoids can be preferred due to their anti-inflammatory (5) and anticancer activities $(6,7)$. High quantities of pentacyclic triterpenoids in Scabiosa species seems to be obvious and there is an evidence that most of the isolated pentacyclic triterpenoids may occur as an aglycone or free acid of saponins (8).

Many researches have been performed currently to study the phar- 


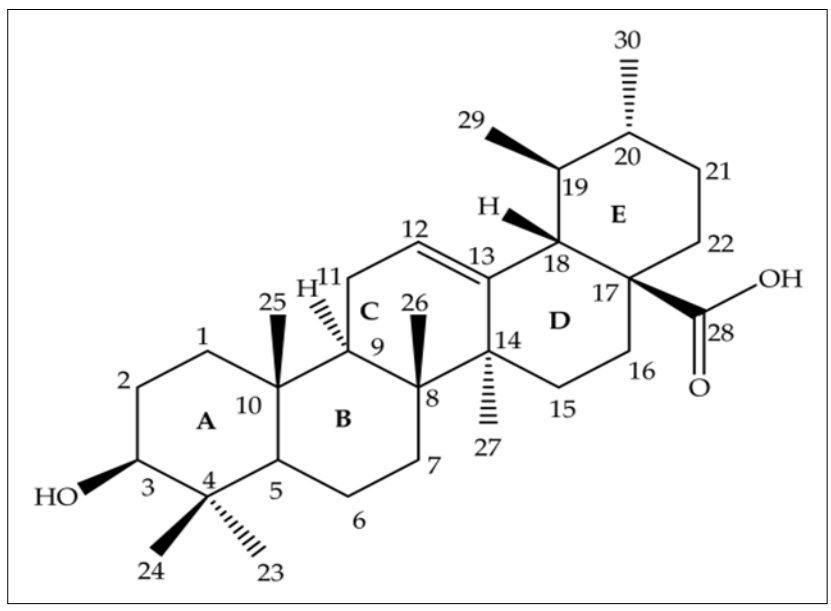

Fig. 1. Ursolic acid chemical structure.

macological value of UA (9). Results shows UA considered as a promising candidate for the development of new medications for management of tumors. In addition, many publications curried out in the last years deal with the usual activities of UA including antitumor $(9,10)$, antidiabetic (11), anti-malarial (12) and anti-atherosclerosis (13) and/or the less common activities like its therapeutic effect on wound by acceleration of healing and regeneration of skin (14) and the inhibition of matrix metalloproteinase-3 (MMP $-3)$.

Due to its low toxicity, anticancer activities, and commercial availability with various structural modifications, UA is regarded as a pillar through organic semisynthesis, and this has attracted more to studying its content in S. palaestina. The aim of our study was to develop a preparative HPLC method for fast screening, isolation and identification of the biologically active pentacyclic triterpenic acid (Ursolic acid) in addition to the quantitative analysis using HPTLC technique in the aerial parts and roots, keeping in mind that other triterpenoids and phytosterols could act as possible interfering compounds.

\section{Materials and Methods}

\section{Plant materials}

Whole plant of $S$ palaestina, which grows as a wild plant in Iraq, were collected during April - May from the north of Kirkuk province and authenticated by the department of Biology, College of Science/Baghdad university. The roots have been separated from aerial parts and both of them were left to dry in shade then grinded using an electric blender, weighted and subsequently subjected to extraction procedures.

\section{Extraction and fractionation}

Approximately $250 \mathrm{~g}$ of aerial parts and roots were subjected for extraction separately using Soxhlet apparatus. each part of $S$ palaestina were extracted using $85 \%$ methanol and the crude extracts were filtered, concentrated under reduced pressure.

Fractionation was done by suspension of the crude extract of aerial parts and roots separately in distilled water. Then well partitioned using petroleum ether (B.P, 60$80^{\circ} \mathrm{C}$ ) and chloroform using $250-500 \mathrm{ml}$ of solvents, the process was repeated three times for each solvent. Later on, chloroform fractions of both plant part were dried using anhydrous sodium sulphate as adsorbent, filtered, evaporated until dryness using rotary evaporator under reduced pressure, weighted and assigned for the isolation of UA.

\section{Detection and quantification of UA by High Performance Thin Layer Chromatography (HPTLC)}

The presence of UA in chloroform fraction of two plant parts (Aerial parts and roots) that obtained by Soxhlet extraction method was detected by HPTLC analysis using $\mathrm{n}$ hexan:ethyl acetate $(5: 1 \mathrm{v} / \mathrm{v})$ as a mobile phase. Qualitative identification was made by comparison of the maximum retardation factor $\left(R_{f}\right)$ and UV spectrum of Ursolic acid in chloroform fraction of each part of S. palaestina with its corresponding standard.

After developing and drying, post-chromatographic derivatization of the plates was performed by spraying the plates by anisaldehyde detection reagent. Then, the plates were heated on a TLC Plate Heater for 2 min at $110^{\circ} \mathrm{C}$. Documentation of the chromatographic plates was done by visual evaluation at $366 \mathrm{~nm}$ (15).

\section{Isolation of UA from chloroform fraction of Iraqi Scabiosa} palaestina

Half $g$ of Chloroform fraction obtained from the aerial parts of Iraqi S. palaestina was dissolved in a minimum quantity of chloroform and injected into preparative HPLC with injection volume of $1 \mathrm{ml}$. Isocratic mobile phase of acetonitrile: methanol $(80: 20 \mathrm{v} / \mathrm{v})$ with an elution volume of $5 \mathrm{ml} / \mathrm{min}$ was selected for identification of UA. The column used C18 (250X10) $5 \mu \mathrm{m}$ particles size. was maintained at $35^{\circ} \mathrm{C}\left( \pm 0.1^{\circ} \mathrm{C}\right)$. And the flow rate: $5 \mathrm{ml} / \mathrm{min}$, UV detection was conducted at $\lambda 210 \mathrm{~nm}$.

\section{Characterization of isolated UA by FT-IR and LC-MS/MS}

LC-MS/MS was carried out in Iraqi National Center for Drug Control and Research (LCMS-8040 series system) Shimadzu, Japan The LC/MS was controlled by chemstation software and equipped with a degasser, binary gradient pump, column thermostat, autosampler, diode array detector (DAD). The liquid chromatography system was coupled with mass spectrometer (LC/MS). For the separation, revers phase analytical column was employed, $\mathrm{C} 18$, length $15 \mathrm{~cm}$, pore size $3.5 \mu \mathrm{m}$, inner diameter (id) $4.6 \mu \mathrm{m}$ and temperature adjusted at $48^{\circ} \mathrm{C}$. The mobile phase was freshly prepared that consist of acetonitrile/20 $\mathrm{mM}$ ammonium acetate containing $0.1 \%$ formic acid $(95 / 5, \mathrm{v} / \mathrm{v})$, the injection volume was $10 \mu \mathrm{l}$, filtered by $0.45 \mu \mathrm{m}$ membrane filter (Millipore) and sonicated before usage. Electrospray ionization (ESI) was performed negative ion mode from $\mathrm{m} /$ z 100e1000, with full and product ion scans and selected ion monitoring.

The FT-IR spectroscopy is a technique deals with the interaction between a molecule and radiation in the IR region of the spectrum (IR region $=4000-400 \mathrm{~cm}-1)$. It was performed in Baghdad national center for drugs control and research, were FT-IR spectroscopy for each isolated constituent was recorded by using Bruker instrument and 
the structural assignments had been correlated for characteristic bands as mentioned in results.

\section{Results and Discussion}

\section{Qualitative and quantitative analysis of UA by HPTLC}

HPTLC is one of the most advanced forms of TLC, efficient for qualitative and quantitative analysis. Automated application of sample prevents the difference in droplet size that may occur when the sample is applied manually and more precise qualitative and quantitative measurements are acquired by automation in different steps increasing the resolution achieved (16). The comparison between the aerial parts and roots of Iraqi S. palaestina that extracted by conventional soxhlet method based on various parameters, like extraction percentage yield obtained and the percentage of bioactive constituents that had been detected by HPTLC analysis of extract fractions for each part, Fig. 2.

HPTLC qualitative and quantitative analysis were applied after extraction to identify and quantify the major proposed percentage of UA in the aerial parts and roots.

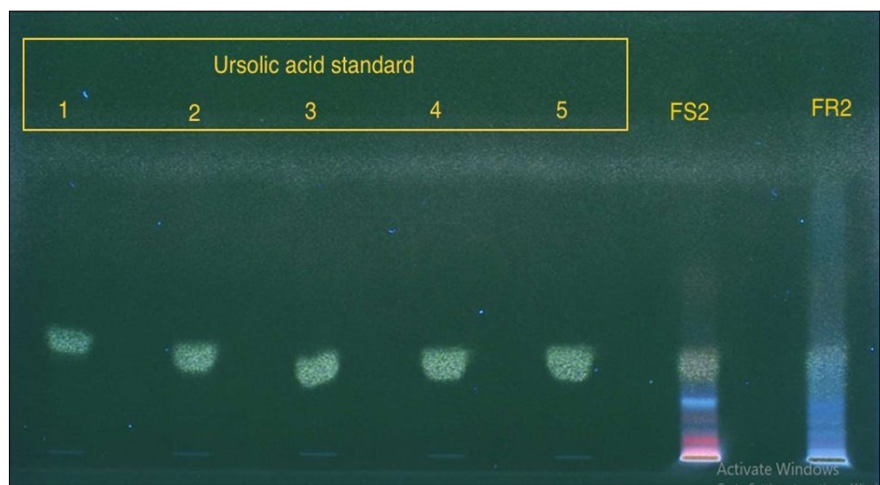

Fig. 2. HPTLC plate of chloroform fraction of aerial parts (FS2) and roots (FR2) of Iraqi Scabiosa palastina L. after derivatization with anisaldehyde spraying reagent at $366 \mathrm{~nm}$.

The presence of compound in chloroform fraction of two plant parts that obtained by Soxhlet extraction method was detected and qualitative identification was made by comparing the maximum retardation factor $\left(R_{f}\right)$ and UV spectrum in chloroform fraction for each part of plant with its corresponding reference standard.

Quantification measurements of UA using the calibration curve that plotted using area under the curve (AUC) versus five concentration levels of reference standard. A straight-line equation was obtained from which the concentration of the UA was calculated in each part of S. palaestina plant as shown in Fig. 3.

uantitative concentration of Ursolic acid in chloroform fraction revealed that aerial parts and roots contain comparable concentrations of 0.052 and $0.054 \mathrm{mg} / \mathrm{ml}$ respectively, as shown in Table 1 . The synthesis and collection of secondary metabolites are very complex and affected by numerous factors including internal factors like developmental genetic circuits (enzymes and regulated gene) and by external environment factors (temperature, light, water, salinity, etc.). Currently, a lot of literatures concentrated on the effect of environmental factors on the synthesis and accumulation of secondary metabolites of medici-

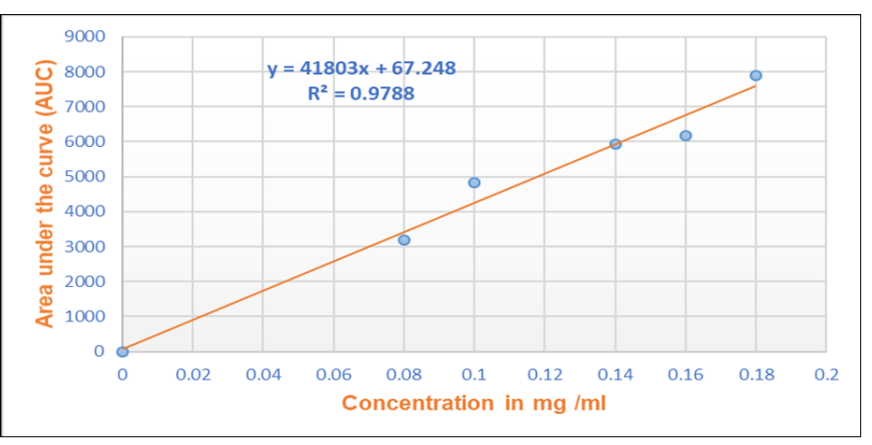

Fig. 3. Calibration curve of UA on High performance thin layer chromatography HPTLC.

Table 1. Quantitative analysis of UA in chloroform fraction of each part of Scabiosa palastina L. by HPTLC

\begin{tabular}{lc}
\hline Part of plant & Concentration $\mathbf{~ m g / m l ~ o f ~ U r s o l i c ~ a c i d ~}$ \\
\hline Aerial parts & 0.052 \\
Roots & 0.054
\end{tabular}

Roots

0.054

nal plants, the effect of the developmental growth and genetic factors on the synthesis and accumulation of secondary metabolites still lack systematic classification (17). UA composed of a C-30 chemical structure built from isoprenoid subunits with $A, B, C, D$ and $E$ rings, may occur as an aglycone or free acid of saponins. The biosynthesis pathway includes folding and cycling squalene from a dammarenyl cation. So, The biosynthesis of Ursolic acid found in plant cells originates from the cyclical (3S) oxidosqualene cycling (18).

\section{Isolation of UA by PHPLC}

Preparative HPLC is used for the isolation and purification of valuable products in the chemical and pharmaceutical industry as well as in biotechnology and biochemistry. Depending on the working area the amount of compound to isolate or purify differs dramatically. It starts in the $\mu \mathrm{g}$ range for isolation of enzymes in biotechnology. At this scale we talk about micro purification. For identification and structure elucidation of unknown compounds in synthesis or natural product chemistry it is necessary to obtain pure compounds in amounts ranging from one to a few $\mathrm{mg}$. HPLC chromatogram of chloroform fractions of the aerial parts and roots gave eleven peaks each one represents a different compound. One of them have similar retention time and UV absorbance, as that of the reference standard UA (8.8 min). The matched compound was collected by fractions collector after monitoring it according to the time (time from the beginning of each peak appearance until disappearance of peak) and labeled as (UA), as shown in Fig. 4.

\section{Characterization of isolated UA}

For structural scan, Full scan product ion liquid chromatography coupled with negative ES ionization spectra was carried out for further characterization of the isolated UA. The effluent from the LC column was directed into the ESI probe. Mass spectrometer conditions were optimized to obtain maximal sensitivity. The ESI was performed in the negative mode, the selection of operating protonated ions is shown in Fig. 5. The scan mode was MRM using the precursor ions at $\mathrm{m} / \mathrm{z}[\mathrm{M}-1]^{-}(\mathrm{m} / \mathrm{z} 455)$ had retention time 9.1 and $9.13 \mathrm{~min}$ for the isolated compound and reference 


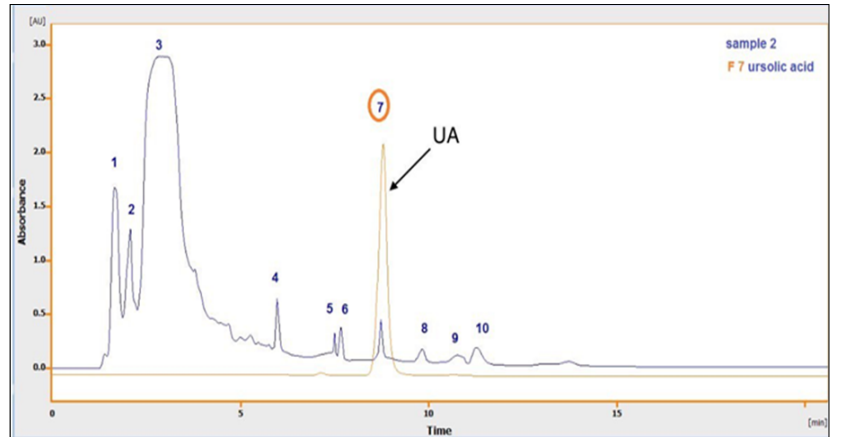

Fig. 4. PHPLC chromatogram for Chloroform fraction. UA, Ursolic acid standard with the matched peak of targeted compound.

standard respectively. These LC/MSMS data were in good agreement with those reported in literatures of UA (19).

Infrared spectroscopy is usually employed to determine the chemical structure of molecules by detecting the vibration of functional groups in the structure of the analyzed compound and is useful for detecting the occurrence

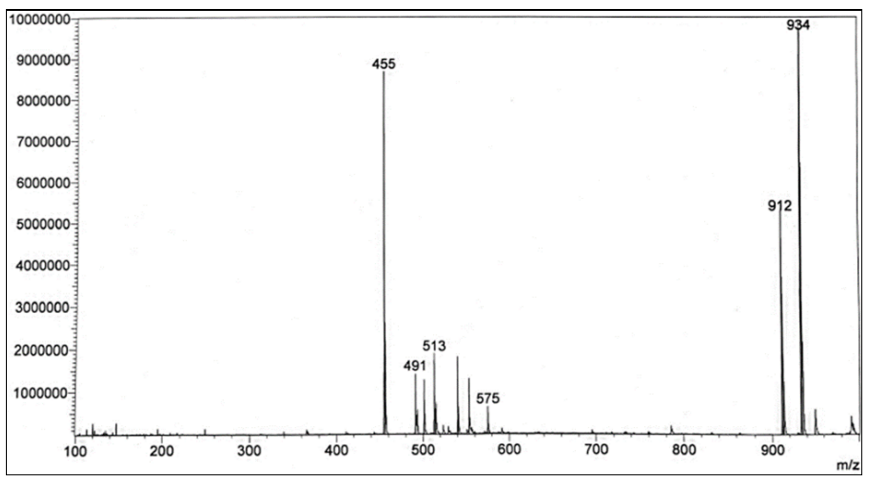

Fig. 5. Representative full scan product ion mass fragmentation spectra of isolated UA.

of intermolecular interactions, which cause changes in the peak positions in the spectrum. FTIR spectra provided in Fig. 5 show a broadened ursolic acid carbonyl peak at around $1689.92 \mathrm{~cm}^{-1}$. OH group spectra of isolated UA appears in the area of $3420.15 \mathrm{~cm}^{-1}$. A very intensive absorption band in the area of $2924.13 \mathrm{~cm}^{-1}$ derives from symmetric vibrations of $\mathrm{CH} 2 \mathrm{~cm}^{-1}$ group. At $1453 \mathrm{~cm}^{-1}$ appears absorption band from $\mathrm{OH}$ vibrations of planar distortion. In the area of $1375.94 \mathrm{~cm}-1$ appears a characteristic ribbon, which derives from $\mathrm{CH} 3$ group and at $1049.5 \mathrm{~cm}^{-1}$ stretching vibrations of $\mathrm{C}-\mathrm{O}$ group of secondary alcohol (20). the characteristic IR absorption bands of the isolated compound are listed in Table 2 and Fig. 6.

Table 2. Characteristic FTIR absorption bands $(\mathrm{cm}-1)$ of the isolated UA

\begin{tabular}{|c|c|c|c|}
\hline \multirow{2}{*}{$\begin{array}{l}\text { Func- } \\
\text { tional } \\
\text { group }\end{array}$} & \multicolumn{2}{|c|}{$\begin{array}{l}\text { Group frequency, wave } \\
\text { number in }(\mathrm{cm}-1)\end{array}$} & \multirow{2}{*}{ Main attributed } \\
\hline & $\begin{array}{l}\text { Isolat- } \\
\text { ed UA }\end{array}$ & $\begin{array}{l}\text { UA stand- } \\
\text { ard }\end{array}$ & \\
\hline $\mathrm{O}-\mathrm{H}$ & 3420.15 & 3434.8 & $\mathrm{O}-\mathrm{H}$ stretching vibration \\
\hline $\mathrm{C}-\mathrm{H}$ & 2924.13 & 2926 & $\mathrm{C}-\mathrm{H}$ stretching in $\mathrm{CH} 3$ and $\mathrm{CH}_{2}$ \\
\hline$C=O$ & 1689.92 & 1693 & $\begin{array}{l}\mathrm{C}=\mathrm{O} \text { stretching of the Carboxyl } \\
\text { group }\end{array}$ \\
\hline $\mathrm{C}-\mathrm{H}$ & 1375.94 & 1350.1 & $\mathrm{C}-\mathrm{H}$ deformation in gem dimethyl \\
\hline $\mathrm{C}-\mathrm{O}$ & 1049.5 & 1059.3 & C-O str. of secondary alcohol \\
\hline
\end{tabular}

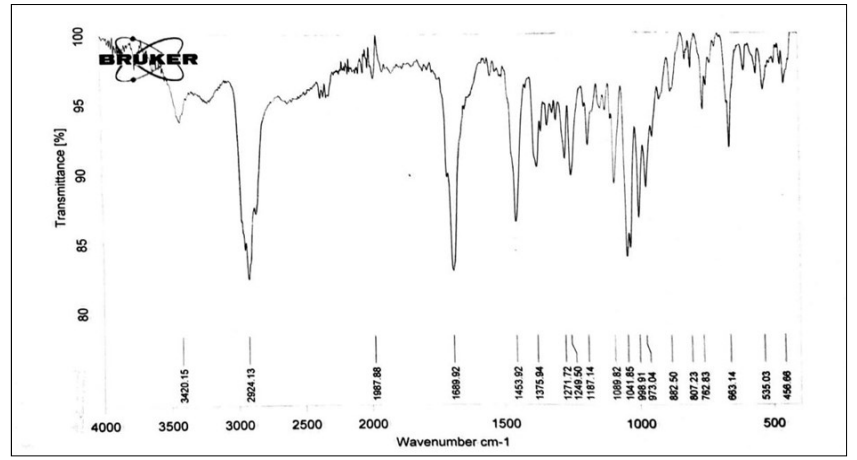

Fig. 6. FTIR spectra of isolated UA.

\section{Conclusion}

The presence and composition of triterpenoids in the roots and aerial parts of Iraqi S. palaestina was determined in this study using different techniques. It was revealed that high concentrations of methanol $85 \%$ extracted from plants considerable amount of triterpenoids which have been concentrated in chloroform fraction of plant extract. Quantitative concentration of UA in chloroform fraction revealed that aerial parts and roots contain comparable concentrations of isolated UA. In addition, LC/MSMS and FT-IR data for the isolated unknown were in good agreement with those reported in literatures of $U A$

\section{Acknowledgements}

The authors would like to thank the College of Pharmacy, Baghdad University and Iraq's National Center for Drug Control and Research for their valuable supports .

\section{Authors' contributions}

The present study was designed by Amjed haseeb khamees. The samples were collected by Enas J khadim from Kirkuk province. All authors performed experiments and handled the research data. Data analysis was conducted by college of pharmacy, Baghdad university and Iraq's National Center for Drug Control and Research.

\section{Compliance with ethical standards}

Conflict of interest: The authors declare that there is no conflict of interest. The authors alone are responsible for the content of the paper. .

Ethical issues: None.

\section{References}

1. George EB, Ronald JT. Toxic Plants of North America; John Wiley and Sons: Oxford, UK, 2013; p. 319-22.

2. Pinto D, Rahmouni N, Beghidja N, Silva A. Scabiosa Genus: A Rich Source of Bioactive Metabolites. Medicines. 2018;5(4):110. https://doi.org/10.3390/medicines5040110

3. Pichersky E, Raguso RA.Why do plants produce so many terpenoid componds? New Phytol. 2016, 2016. https:// doi.org/10.1111/nph.14178

4. Singh B, Sharma RA. Plant terpenes: Defense responses, phylogenetic analysis, regulation and clinical applications. 3 Biotech 2015, 5, 129-51. https://doi.org/10.1007/s13205-014-0220-2 
5. Yadav VR, Prasad S, Sung B, Kannappan R, Aggarwal BB. Targeting Inflammatory Pathways by Triterpenoids for Prevention and Treatment of Cancer. 2010;2428-66. https://doi.org/10.3390/ toxins 2102428

6. Kamble SM, Goyal SN, Patil CR. RSC Advances Multifunctional pentacyclic triterpenoids as adjuvants in cancer chemotherapy: a review. RSC Adv [Internet]. 2014;4:33370-82. https:// doi.org/10.1039/C4RA02784A

7. Chudzik M, Korzonek-szlacheta I, Król W. Triterpenes as potentially cytotoxic compounds. 2015;1610-25. https:// doi.org/10.3390/molecules20011610

8. Jäger S, Trojan H, Kopp T, Laszczyk MN, Scheffler A. Pentacyclic triterpene distribution in various plants - Rich sources for a new group of multi-potent plant extracts. 2016;2016-31. https:// doi.org/10.3390/molecules 14062016

9. Ayeleso TB, Matumba MG, Mukwevho E. Oleanolic acid and its derivatives: Biological activities and therapeutic potential in chronic diseases. Molecules. 2017;22(11). https:// doi.org/10.3390/molecules22111915

10. Gao YS, Yuan Y, Song G, Lin SQ. Inhibitory effect of ursolic acid and oleanolic acid from Eriobotrya fragrans on A549 cell viability in vivo. Genet Mol Res. 2016;15(2):1-8. https://doi.org/10.4238/ gmr.15028642

11. Xue S, Yin J, Shao J, Yu Y, Yang L, Wang Y et al. A syntheticbiology-inspired therapeutic strategy for targeting and treating hepatogenous diabetes. Mol Ther [Internet]. 2017;25(2):443-55. https://doi.org/10.1016/j.ymthe.2016.11.008

12. Beaufay C, Hérent MF, Quetin-Leclercq J, Bero J. In vivo antimalarial activity and toxicity studies of triterpenic esters isolated from Keetia leucantha and crude extracts. Malar J. 2017, 16, 406. https://doi.org/10.1186/s12936-017-2054-y

13. Pan $\mathrm{Y}$, Zhou $\mathrm{F}$, Song $Z$, Huang $H$, Chen $\mathrm{Y}$, Shen $\mathrm{Y}$ et al. Oleanolic acid protects against pathogenesis of atherosclerosis, possibly via FXR-mediated angiotensin (Ang)-(1-7) upregulation. Biomed Pharmacother [Internet]. 2018;97(August 2017):1694-700. https://doi.org/10.1016/j.biopha.2017.11.151
14. Bernabé-García Á, Armero-Barranco D, Liarte S, Ruzafa-Martínez $M$, Ramos-Morcillo AJ, Nicolás FJ. Oleanolic acid induces migration in Mv1Lu and MDA-MB-231 epithelial cells involving EGF receptor and MAP kinases activation. PLoS One. 2017;12(2):1-24. https://doi.org/10.1371/journal.pone.0172574

15. Naumoska K, Simonovska B, Albreht A, Vovk I. TLC and TLC-MS screening of ursolic, oleanolic and betulinic acids in plant extracts. J Planar Chromatogr - Mod TLC. 2013;26(2):125-31. https://doi.org/10.1556/JPC.26.2013.2.4

16. Al-Dahan N. Phytochemical investigation of Melia azedarach cultivated in Iraq. Pharmacognocy, MSc thesis, Baghdad university; 2016.

17. Li Y, Kong D, Fu Y, Sussman MR, Wu H. The effect of developmental and environmental factors on secondary metabolites in medicinal plants. Plant Physiology and Biochemistry. 2020 Mar 1;148:80-89. https://doi.org/10.1016/j.plaphy.2020.01.006

18. Pironi AM, Araújo PR De, Fernandes MA. Characteristics, biological properties and analytical methods of ursolic acid: a review. 2017;8347(October). doi.org/10.1080/10408347.2017.1390425

19. Tan ZR, Chen Y, Zhou G, Cao S, Peng XD, Wang YC et al. LC-MS-MS quantitative determination of ursolic acid in human plasma and its application to pharmacokinetic studies. Chromatographia. 2010;72(11-12):1107-13. https://doi.org/10.1365/s10337-010$1797-1$

20. Abd AM, Kadhim EJ. Phytochemical investigation of aerial parts of Iraqi Cardaria draba. Iraqi Journal of Pharmaceutical Sciences. 2020 Dec 27;29(2):27-36. https://doi.org/10.31351/vol29iss2pp2736

$\S \S \S$ 